\title{
Honeycomb-Structured Porous Films Controlled by the Temperature of Water Bath
}

\author{
By Benqiao HE, ${ }^{*}$ Jianxin LI, Xuejing ZHANG, Zhenxing LI, Yajun HoU, and Changjiang SHI
}

The highly ordered porous films were fabricated from the solution of polystyrene with one carboxyl terminal group in carbon disulfur in a chamber with a water bath. It is found that the pore size can be readily controlled by changing the temperature of water bath. The pore size increases with an increase in the water-bath temperature in a given range. And the porous film from the "dilute" solution can be readily formed even at a low relative humidity (RH), while the porous film from the "concentrated" solution can be fabricated only at a rather high RH. The regularity of porous film becomes better at the higher $\mathrm{RH}$ and higher concentration. It suggests that there exists a synergetic effect of solution concentration and RH on the formation of porous film. These phenomena are explained by the slow evaporation rate of the solvent under the conditions. KEY WORDS: Porous Film / Breath Figures / Polystyrene / Control of Pore Size /

Porous films have attracted increasing attention as functional materials in various fields such as biotechnology ${ }^{1-4}$ and photonics. $^{5,6}$ A variety of templating methods have been developed to create ordered pores with dimensions of tens to thousands of nanometers, such as colloidal crystals, ${ }^{7,8}$ selfassembly of emulsions or surfactants,,${ }^{9,10}$ microphase-separation of block copolymers. ${ }^{11,12}$ The templates employed in the methods are often sacrificial, though they are not readily produced. ${ }^{13-16}$ Recently, a breath figures (BF) method in which water droplets act as easily available templating medium draws increasing interests. ${ }^{17-19}$ In this method, the evaporation of solvent in polymer solution leads to a decrease in the temperature of solution surface, and water vapor starts to condense onto the cold solution surface to form water droplets. And then the water droplets are packed by the precipitated polymers and self-assembled into a BF array. Upon further evaporation of solvent and water, the ordered porous structure is effectively locked in place. ${ }^{17}$ The morphology of pores mocking the water droplets can be readily controlled by varying the process conditions (such as relative humidity, concentration and airflow rate across the polymeric solution surface, etc.) and the types of materials used. ${ }^{17,19-22}$ The basic techniques related to BF method also markedly affected the formation of pores. In the airflow technique, an airflow parallelly across the solution surface results in cooling of solution surface due to fast evaporation of the solvent, which is beneficial to formation of highly ordered porous film and widely used in BF method. ${ }^{19,20,23}$ Recently, Li et al. ${ }^{24}$ developed a new method that the airflow blew across the solution surface along the direction having a small angle with respect to the normal of the solution surface. The shape of the pores could be controlled, that is, elliptical pore morphology with different aspect ratios was obtained. Stenzel et al. ${ }^{25}$ switched the airflow from parallel to vertical stream, better porous size control over the whole film surface was achieved, but at the cost of regularity of the film. In the above techniques, the airflow containing a certain amount of moisture, which is often additionally fed, played a key role in inducing a decrease in solution temperature and the formation of ordered porous film. Bormashenko et al. ${ }^{26,27}$ employed a fast dip-coating technique to fabricate porous film on different solid substrates. They found that the drying temperature markedly affected the morphology of porous film and the air humidity was not the crucial role in the formation of porous film. In a word, the smart techniques used make it convenient and powerful in the control of morphology and the processing of the porous film. ${ }^{28-30}$

In the present paper, we directly fabricated the porous film in a chamber with a water bath without an additional fed airflow. The control of morphology of porous films was achieved by changing the temperature of water bath in the chamber so as to adjust the relative humidity and air temperature in the chamber. We showed how to facilely control the relative humidity of the chamber to simultaneously control the pore size. We also presented the synergetic effect of solution concentration and relative humidity on the formation and morphology of porous film.

\section{EXPERIMENT}

Linear polystyrene with one carboxyl terminal group (PSc) was purchased from Scientific Polymer Products, INC (www.scientificpolymer.com) and used as received. The weight-average molecular weight is 50000. PSc/Carbon disulfur $\left(\mathrm{CS}_{2}\right)$ solutions with concentrations of $5,10,20,40$, 60 and $80 \mathrm{mg} / \mathrm{ml}$ were prepared at room temperature. The experiment setup was shown in Figure 1. The column chamber with a diameter of $20 \mathrm{~cm}$ and a height of $20 \mathrm{~cm}$ had a movable cover. A clean glass slide was placed on a plastic platform in a chamber. The distance between the glass slide and water

Tianjin Key Laboratory of Fiber Modification and Functional Fiber, School of Material Science and Chemical Engineering, Tianjin Polytechnic University, Tianjin 300160, China

*To whom correspondence should be addressed (Tel: +86-22-24528055, Fax: +86-22-24528055, E-mail: hebenqiao@tjpu.edu.cn). 


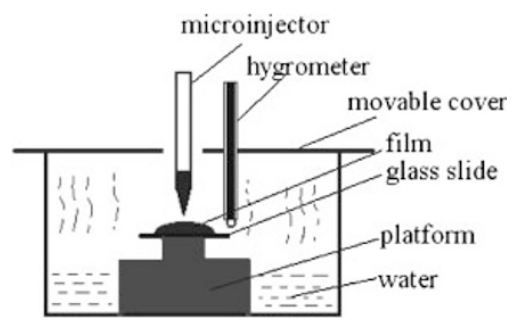

Figure 1. The schematic image of experiment setup.

Table I. The air $\mathrm{RH}$ and air temperature $\left(T_{\mathrm{S}}\right)$ near glass slide as a function of water-bath temperature $\left(T_{\mathrm{w}}\right)$ in the chamber without a cover in moist air

\begin{tabular}{cccccc}
\hline$T_{\mathrm{w}}\left({ }^{\circ} \mathrm{C}\right)$ & 20 & 42 & 60 & 84 & 90 \\
\hline$R H / T_{\mathrm{s}}\left({ }^{\circ} \mathrm{C}\right)$ & $60 \% / 20$ & $75 \% / 26$ & $84 \% / 29$ & $99 \% / 35$ & $99 \% / 42$ \\
\hline
\end{tabular}

surface is about $5 \mathrm{~cm}$. And the distance between glass slide and the cover is about $10 \mathrm{~cm}$. A certain amount of solution was dropped and spread on a glass slide through using a microinjector.

The relative humidity $(\mathrm{RH})$ was adjusted by changing the temperature of water bath or vent size of chamber. The RH value in the chamber increased with an increase in temperature of water bath and a decrease in the vent size of chamber (see Table I). The relative humidity and the temperature near the glass slide were supervised by using a Traceable Hygromater (Control Company, USA). The surface morphology of the porous films was investigated by optical microscope (OP) (Olympus, BX51).

\section{RESULTS AND DISCUSSION}

\section{The Effects of Water-bath Temperature}

Figure 2 shows the OP images of PSc porous film fabricated from $20 \mathrm{mg} / \mathrm{mL} \mathrm{PSc} / \mathrm{CS}_{2}$ solution in the chamber with different water-bath temperatures in moist air. The highly ordered, honeycomb-structured porous films are observed. And it is found that the pore size is increased with an increase in water-bath temperature, that is, the pore diameter increases from 1.4 to $3.3 \mu \mathrm{m}$ when the water-bath temperature rises from $20^{\circ} \mathrm{C}$ to $84^{\circ} \mathrm{C}$. Higher water-bath temperature, such as $90^{\circ} \mathrm{C}$, leads to irregular structure with different sizes (not shown here). The phenomena should be mainly related to the variation of the water-bath temperature. The increase in water-bath temperature leads to an increase in the $\mathrm{RH}$ and environmental temperature near glass slide in the chamber (the results are shown in Table I), which strongly affects the quality of porous film and pore size. High environmental temperature improving the evaporation rate of solvent leads to the cooler solution surface, which helps to the nucleation of water droplets. And high $\mathrm{RH}$ is beneficial to nucleation and growth of water droplets. ${ }^{17,21}$ In our experiment, these factors are simultaneously controlled by the variation of water-bath temperature. Therefore, an increase in pore size with increasing the waterbath temperature is observed. However, when the water-bath temperature is increased up to $90^{\circ} \mathrm{C}$ (the environmental temperature is about $42^{\circ} \mathrm{C}$ near the boiling point of the solution), a disordered porous film with different pore sizes is obtained though the $\mathrm{RH}$ is the same as that at $84{ }^{\circ} \mathrm{C}$ (see
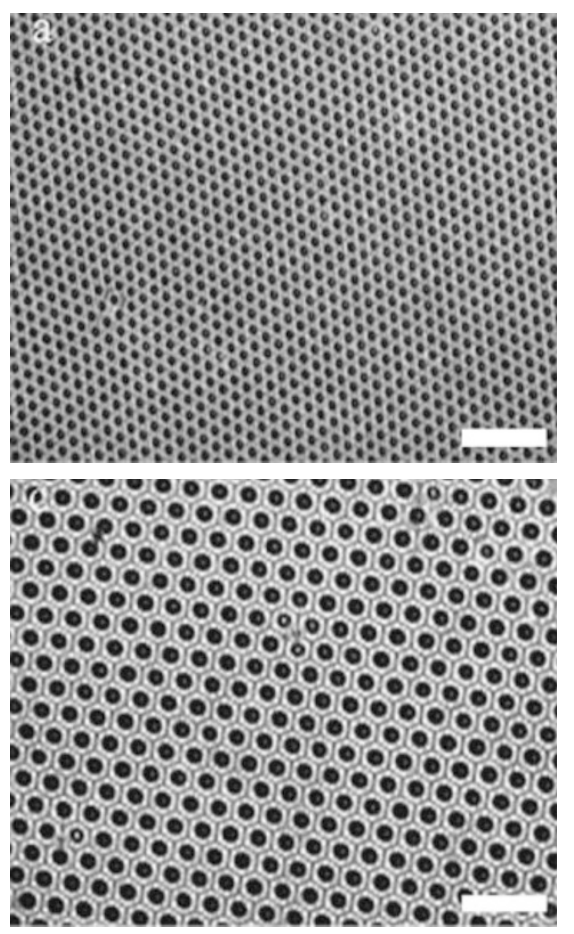
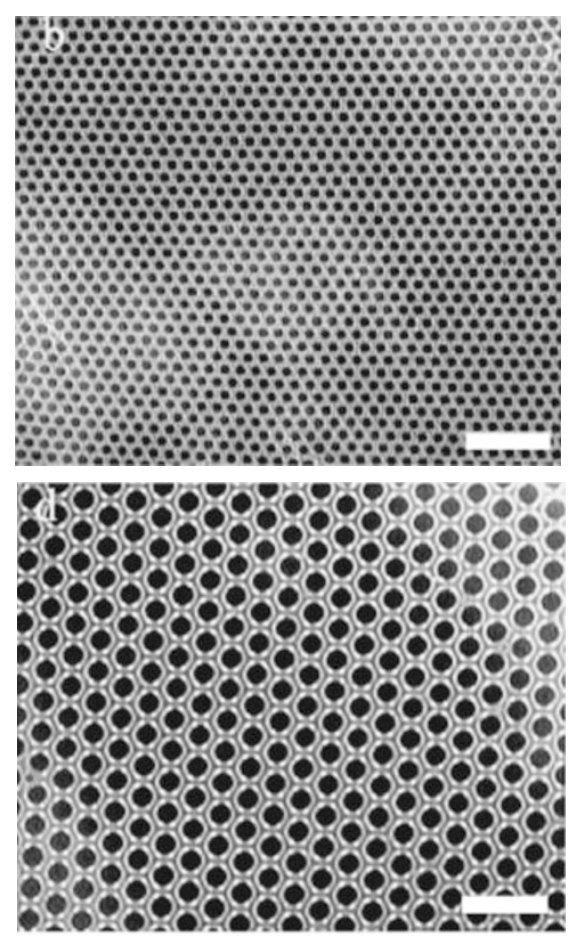

Figure 2. The reflective OP images of the porous films prepared at different water-bath temperatures (a) $20^{\circ} \mathrm{C},(\mathrm{b}) 42^{\circ} \mathrm{C},(\mathrm{c}) 60^{\circ} \mathrm{C}$ and $(\mathrm{d}) 84^{\circ} \mathrm{C}$. The $\mathrm{PSc} / \mathrm{CS} 2$ solution is $20 \mathrm{mg} / \mathrm{mL}$, spreading volume is $25 \mu \mathrm{l}$. The scale bar is $10 \mu \mathrm{m}$. 


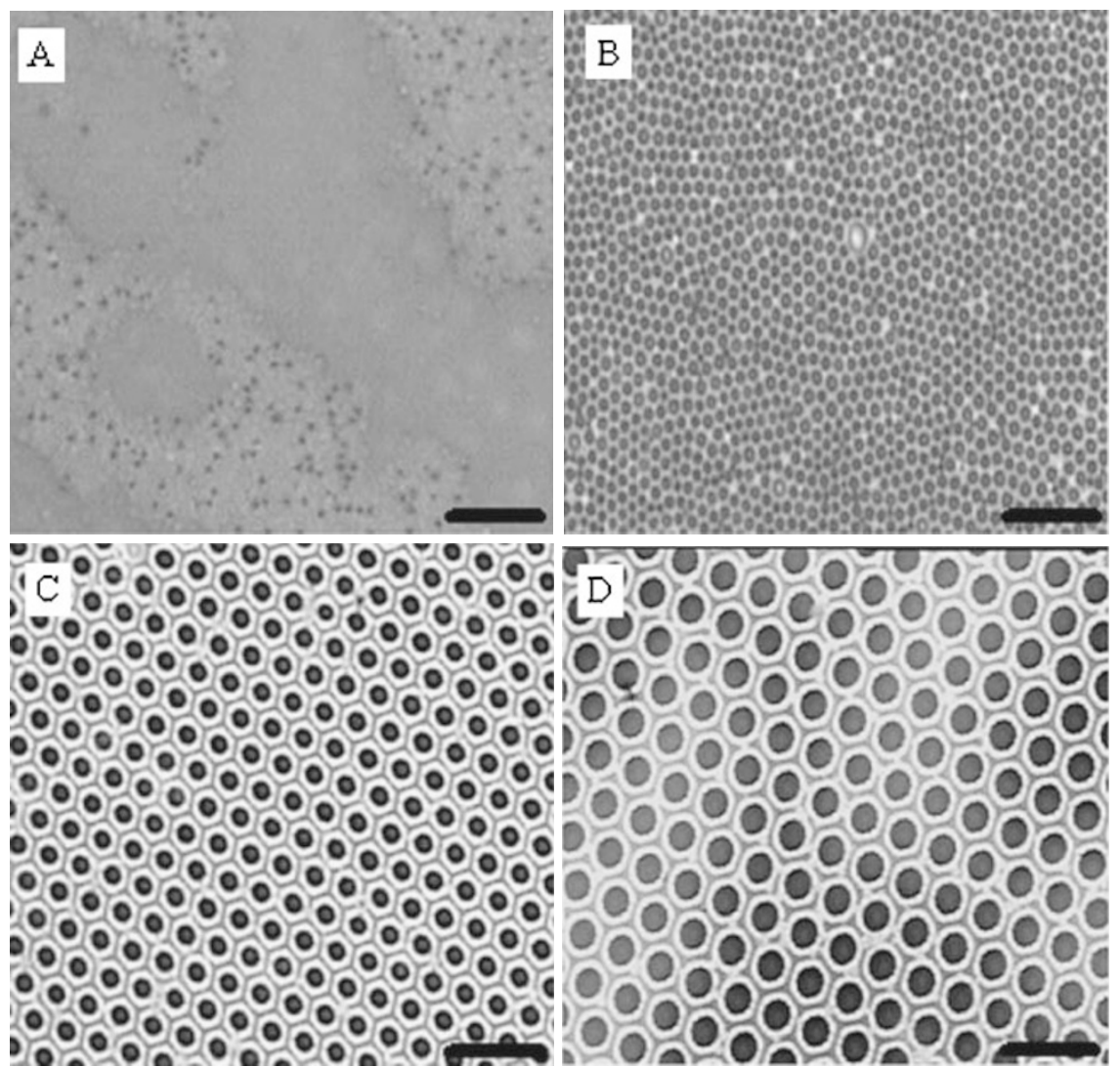

Figure 3. The relationship between morphology of porous structure and the $\mathrm{RH}$ of $35 \%(\mathrm{~A}), 50 \%(\mathrm{~B}), 75 \%(\mathrm{C})$ and $99 \%(\mathrm{D})$. Other conditions are: concentration $20 \mathrm{mg} / \mathrm{ml}$, spreading volume $25 \mu \mathrm{l}$, temperature of water bath $44^{\circ} \mathrm{C}$. The scale bar is $10 \mu \mathrm{m}$.

Table I). It suggests that too high air temperature (near the boiling point of the solution) is disadvantage of the formation of ordered porous film.

\section{The Effects of Relative Humidity}

Figure 3 shows the morphology of film from $20 \mathrm{mg} / \mathrm{ml}$ $\mathrm{PSc} / \mathrm{CS}_{2}$ solution at different RHs that are obtained by varying the vent size at the water-bath temperature of $44{ }^{\circ} \mathrm{C}$ in dry winter. The RH values from $35 \%$ to saturated humidity $(99 \%$ shown in hygroscope) can be achieved by changing the vent size from full open state to $1 / 5$ open state. At lower RH (35\%), that is, at full open state, only small disordered porous structure in some areas is obtained (in Figure 3a). This is because the $\mathrm{RH}$ is so low that it is difficult to reach the dew point of water vapor and then to form water-droplet template. At the RH of above $50 \%$, the pore size increases. ${ }^{17,19,31}$ And the regularity of porous film becomes better. At saturated humidity (99\%), the film with big pore size and well regularity is obtained, which is different from others' reports that no ordered porous structure could be obtained at high $\mathrm{RH} .{ }^{19}$ It is probably due to slow evaporation of solvent (comparing with the additional airflow technique ${ }^{19,20,23}$ ) leading to a slow increase in viscosity of the solution. A longer time of convection and a low flow resistance of water droplets in solution surface occur, which help to formation of highly ordered porous film.

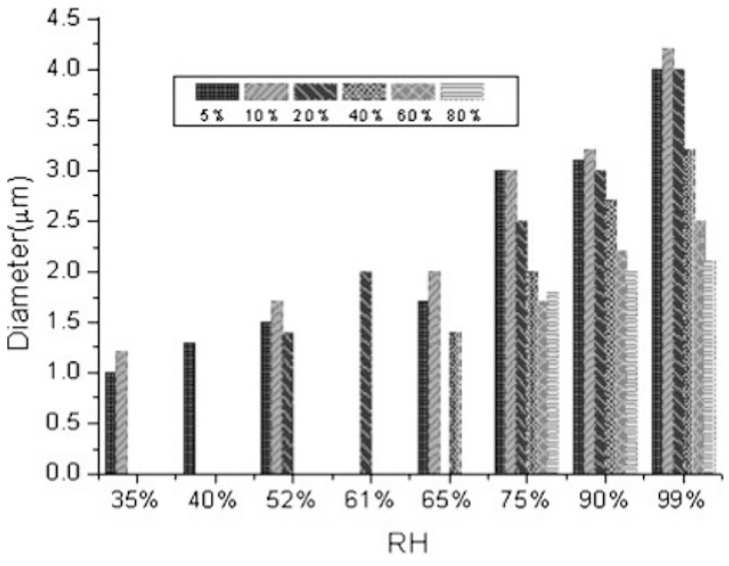

Figure 4. The pore size of films from solutions with different concentrations at different relative humidity. Water-bath temperature is $44^{\circ} \mathrm{C}$ spreading volume is $25 \mu \mathrm{l}$. The insert stands for the concentrations of the solutions.

We also investigate the porous film from $\mathrm{PSc} / \mathrm{CS}_{2}$ solutions with different concentrations at different RHs. The results are shown in Figure 4. The porous structure fabricated from 5 and $10 \mathrm{mg} / \mathrm{ml}$ solutions can be formed even at a very low RH (about 35\%), though it is somewhat disordered. And for the 20 and $40 \mathrm{mg} / \mathrm{ml}$ solutions, the porous structure can be obtained at a $\mathrm{RH}$ of above $52 \%$, respectively. The porous structure from 60 


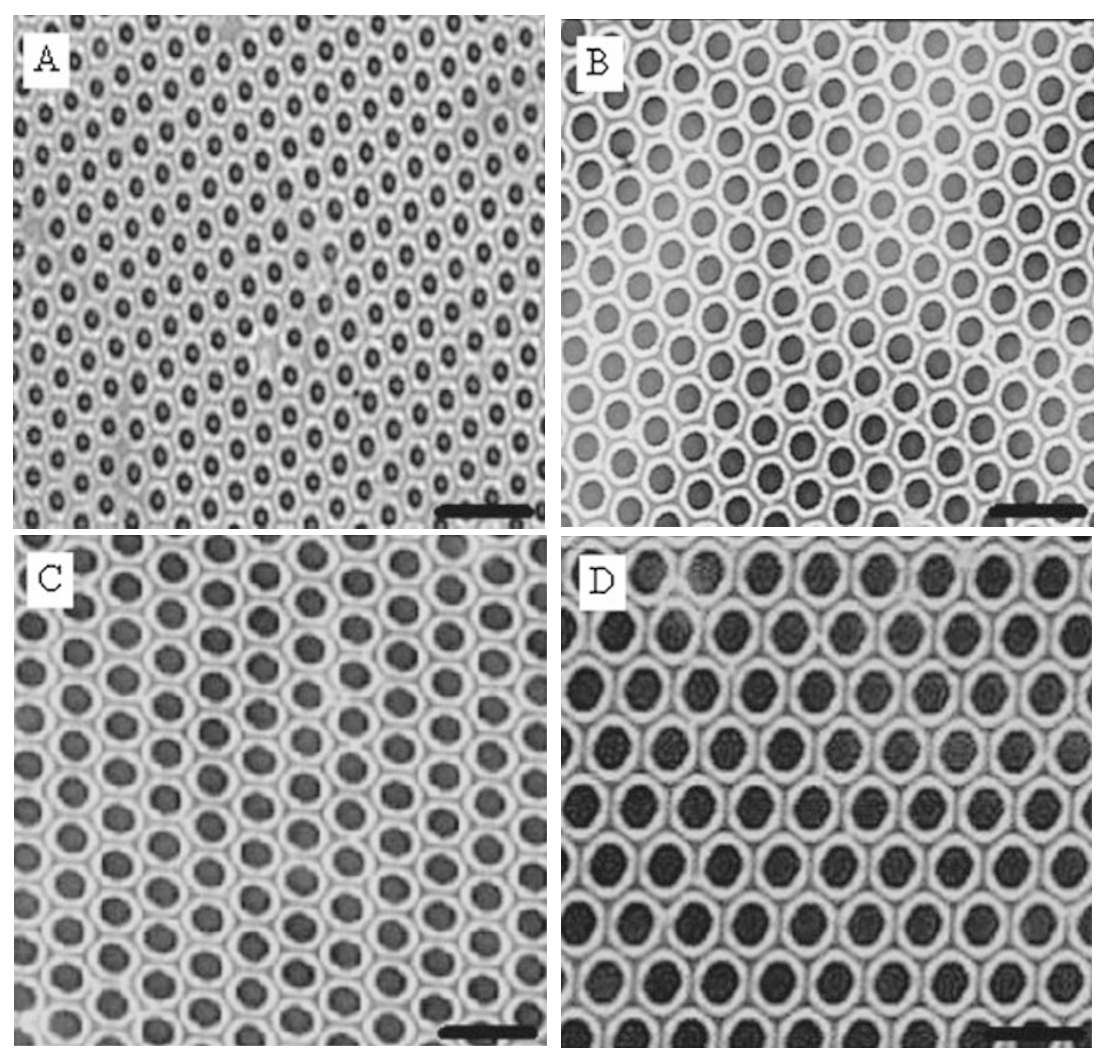

Figure 5. The variation of pore size as the volume of casting solution, A. $10 \mu \mathrm{l}, \mathrm{B} .25 \mu \mathrm{l}, \mathrm{C} .50 \mu \mathrm{l}, \mathrm{D} .100 \mu \mathrm{l}$. Other conditions: $20 \mathrm{mg} / \mathrm{ml} \mathrm{PSc} / \mathrm{CS}$, $99 \%$ RH, waterbath temperature $44^{\circ} \mathrm{C}$. The scale bar is $10 \mu \mathrm{m}$.

and $80 \mathrm{mg} / \mathrm{ml}$ solutions can be formed at a rather high $\mathrm{RH}$ (above $75 \%$ ). Porous films from the solutions with a concentration range of $5-80 \mathrm{mg} / \mathrm{ml}$ are easily formed at high $\mathrm{RH}$ $(\geq 75 \%)$. But it is difficult for the solution with higher concentration to form ordered porous film at a low RH. This phenomenon can be explained by the variation of vapor pressure of the solution. According to the Henry law, the vapor pressure of dilute solution is higher than that of concentrated one. The high vapor pressure of dilute solution producing the high evaporation rate of solvent results in the cooler solution surface that easily reaches the dew point of water vapor even at a lower RH. Therefore, water vapor can be condensed on the surface of solution film to form porous structure. While for the solution with a high concentration, the vapor pressure is low, resulting in a low evaporation rate to yield a little temperature drop. The temperature drop is too little to reach the dew point of air with a low RH. Therefore, no condensed water droplets can be formed in a low RH air, and nonporous film is obtained in concentrated solution. Evidently, there exists a synergetic effect of solution concentration and $\mathrm{RH}$ on the formation of porous structure.

From Figure 4, The pore size decreases with increasing the solution concentration except for $5 \mathrm{mg} / \mathrm{ml}$ solution, which accords with the general rule obtained by other authors. ${ }^{17,19,21,32}$ For the porous film from $5 \mathrm{mg} / \mathrm{ml}$ solution, the pore size is somewhat smaller than that from $10 \mathrm{mg} / \mathrm{ml}$ solution, which is abnormal. Furthermore, the regularity of porous structure is poorer than that from higher concentration of the solution. These phenomena may be related to the low viscosity of the dilute solution. The dilute solution with low initial viscosity spreads faster than the concentrated ones on the substrate and results in a large casting area. It would be expected to have a shorter time of solvent evaporation, which is disadvantage of the convection of water droplets and the growth of water droplets. Therefore, smaller and disordered pores are obtained.

\section{The Effects of Casting Volume}

Figure 5 shows the relationship between the pore size and the casting volume. The pore size changes from 2.5 to $6.5 \mu \mathrm{m}$ when the casting volume ranges from 10 to $100 \mu \mathrm{l}$, which accords with other results. ${ }^{17,33}$ The pore size depends on the amount of solution initially cast on the glass substrates, with pore size being proportional to the amount of polymer solution cast. The reason for the increase in pore size for larger casting volumes is the longer evaporation time of solvent that results in a longer growth time of water droplets, in which bigger pore sizes are obtained. It is a good way to fabricate the film with big pore size. ${ }^{34}$

We also investigated the BF array of other polymers, such as polyfluorenes, poly(methyl mathacrylate). Under our experiment conditions, high-quality porous films from the polymers/ $\mathrm{CS}_{2}$ solution were obtained. But when other vaporizable solvents, such as toluene and dichloromethane, were used, only transparent film was obtained and no porous structure was 
observed even at rather high $\mathrm{RH}(80 \%)$, which is different from the results reported in literatures. ${ }^{23}$ It is possibly because the slower evaporation rate of toluene or dichloromethane (with respect to the conditions in the literature ${ }^{23}$ ) yields too little temperature drops of the solution surface to condense the water vapor to form water droplets. At saturated $\mathrm{RH}$, only disordered porous film with different pore sizes were obtained, which need further study in the future.

In conclusion, the highly ordered porous films were readily fabricated in a chamber with a water bath. And the RH is easily adjusted by changing the water-bath temperature or vent size, which controls the pore size. The pore size increases with an increase in the water-bath temperature and the volume of casting solution, and a decrease in the vent size. The porous film from the "dilute" solution can be readily formed even at a low RH, while the porous film from the "concentrated" solution can be fabricated only at a rather high RH. The regularity of porous film becomes better at the higher $\mathrm{RH}$ and the higher solution concentration, which may result from the slow evaporation rate of solvent in our technique. It suggests that there is a synergetic effect of concentration and $\mathrm{RH}$ on the formation of ordered porous film. We believe that it is a more convenient and more powerful technique to prepare honeycomb-structured porous film.

Acknowledgment. The financial support by National Natural Science Foundation of China (Grant No. 20676100), Tianjin Natural Science Foundation (Grant No. 08JCYBJC26400 and 08JCZDJC24000), Open Foundation of State Key Laboratory of Polymer Physics \& Chemistry (Grant No. 200607) and Program for New Century Excellent Talents in University (Grant No. NCET-06-0250) is gratefully acknowledged. We would also like to thank Prof. Young-Baek Kim in the Department of Nanotechnology, PaiChai University, Daejon 302-735, South Korea, for support.

Received: July 11, 2008 Accepted: September 5, 2008 Published: October 22, 2008

\section{REFERENCES}

1. B. Xiao, P. S. Wheatley, X. B. Zhao, A. J. Fletcher, S. Fox, A. G. Rossi, I. L. Megson, S. Bordiga, L. Regli, K. M. Thomas, and R. E. Morris, J. Am. Chem. Soc., 129, 1203 (2007).

2. L. A. Connal, Aust. J. Chem., 60, 794 (2007).

3. D. Losic, G. Triani, P. J. Evans, A. Atanacio, J. G. Mitchell, and N. H. Voelcker, J. Mater. Chem., 16, 4029 (2006).

4. Y. L. Khung, S. D. Graney, and N. H. Voelcker, Biotechnol. Prog., 22, 1388 (2006)

5. E. Trave, F. Enrichi, G. Mattei, V. Bello, E. Borsella, F. Fabbri, M. Carpanese, M. Falconieri, C. Abate, F. Costa, L. Costa, and L. Gini,
“Advanced Laser Technologies," SPIE-International Society for Optical Engine, 2005, p 5850.

6. F. Kong, G. Huang, Y. Yang, C. Yang, X. Wu, X. Bao, and R. Yuan, Chin. J. Luminescence, 26, 785 (2005).

7. M. A. Al-Daous and A. Stein, Chem. Mater., 15, 2638 (2003).

8. Z. Q. Sun, X. Chen, J. H. Zhang, Z. M. Chen, K. Zhang, X. Yan, Y. F. Wang, W. Z. Yu, and B. Yang, Langmuir, 21, 8987 (2005).

9. D. R. Greve, N. Reitzel, T. Hassenkam, J. Bogelund, K. Kjaer, P. B. Howes, N. B. Larsen, M. Jayaraman, R. D. McCullough, and T. Bjornholm, Synth. Met., 102, 1502 (1999).

10. J. T. Luo, W. F. Wu, H. C. Wen, B. Z. Wan, Y. M. Chang, C. P. Chou, J. M. Chen, and W. N. Chen, Thin Solid Films, 515, 7275 (2007).

11. S. Ohya, Y. Fujii, and S. Yao, Nihon Reoroji Gakkaishi, 35, 93 (2007).

12. P. Leclere, D. Marsitzky, V. Francke, S. Setayesh, K. Mullen, J. L. Bredas, and R. Lazzaroni, Adv. Mater., 12, 1042 (2000).

13. N. Cohen-Hadar, Y. Wine, E. Nachliel, D. Huppert, M. Gutman, F. Frolow, and A. Freeman, Biotechnol. Bioeng., 94, 1005 (2006).

14. A. B. Fuertes and S. Alvarez, Carbon, 42, 3049 (2004).

15. W. P. Guo, J. W. Park, and C. S. Ha, "Metal-Containing and Metallosupramolecular Polymers and Materials," American Chemical Society Publication, 2006, p 486.

16. Y. Y. Lyu, J. H. Yim, Y. Byun, J. M. Kim, and J. K. Jeon, Thin Solid Films, 496, 526 (2006).

17. U. H. F. Bunz, Adv. Mater., 18, 973 (2006).

18. C. Greiser, S. Ebert, and W. A. Goedel, Langmuir, 24, 617 (2008).

19. B. Zhao, C. X. Li, Y. Lu, X. D. Wang, Z. L. Liu, and B. H. Zhang, Polymer, 46, 9508 (2005).

20. D. Nystrom, P. Antoni, E. Malmstrom, M. Johansson, M. Whittaker, and A. Hult, Macromol. Rapid. Comm., 26, 524 (2005).

21. M. H. Stenzel, C. Barner-Kowollik, and T. P. Davis, J. Polym. Sci. Polym. Chem. Ed., 44, 2363 (2006).

22. L. Song, R. K. Bly, J. N. Wilson, S. Bakbak, J. O. Park, M. Srinivasarao, and U. H. F. Bunz, Adv. Mater., 16, 115 (2004).

23. M. Srinivasarao, D. Collings, A. Philips, and S. Patel, Science, 292, 79 (2001).

24. J. Li, J. Peng, W. H. Huang, Y. Wu, J. Fu, Y. Cong, L. J. Xue, and Y. C. Han, Langmuir, 21, 2017 (2005).

25. K. H. Wong, M. Hernandez-Guerrero, A. M. Granville, T. P. Davis, C. Barner-Kowollik, and M. H. Stenzel, J. Porous Mater., 13, 213 (2006).

26. E. Bormashenko, R. Pogreb, O. Stanevsky, Y. Biton, Y. Bormashenko, V. Streltsov, and Y. Socol, presented at Icecs 2004: $11 \mathrm{Th}$ Ieee International Conference on Electronics, Circuits and Systems, 2004.

27. E. Bormashenko, R. Pogreb, O. Stanevsky, Y. Biton, and Y. Bormashenko, J. Mater. Sci., 39, 6639 (2004).

28. A. Bolognesi, C. Mercogliano, S. Yunus, M. Civardi, D. Comoretto, and A. Turturro, Langmuir, 21, 3480 (2005).

29. M. S. Park, W. Joo, and J. K. Kim, Langmuir, 22, 4594 (2006).

30. M. S. Park and J. K. Kim, Langmuir, 20, 5347 (2004).

31. L. Cui, J. Peng, Y. Ding, X. Li, and Y. C. Han, Polymer, 46, 5334 (2005).

32. L. H. Wang, Y. Tian, H. Y. Ding, and B. Q. Liu, Eur. Polym. J., 43, 862 (2007).

33. T. Nishikawa, R. Ookura, J. Nishida, T. Sawadaishi, and M. Shimomura, Riken Review, 37, 43 (2001).

34. H. Yabu, M. Tanaka, K. Ijiro, and M. Shimomura, Langmuir, 19, 6297 (2003). 